Goldschmidt 2021 Abstract

https://doi.org/10.7185/gold2021.7056

\section{Microbial ecology of intracellular calcium carbonate biomineralization by bloom-forming cyanobacteria}

\author{
JULIETTE GAËTAN ${ }^{1}$, NEHA MEHTA ${ }^{2}$, ELODIE \\ DUPRAT $^{3}$, APOLLINE BRULEY $^{4}$, FÉRIEL SKOURI- \\ PANET $^{5}$, MURIEL GUGGER $^{6}$, CÉCILE BERNARD $^{7}$, \\ CHARLOTTE DUVAL $^{8}$, JULIE LELOUP ${ }^{9}$ AND KARIM \\ BENZERARA $^{10}$
}

${ }^{1}$ CNRS - IMPMC

${ }^{2}$ Sorbonne University

${ }^{3}$ IMPMC, CNRS, Sorbonne Université, MNHN

${ }^{4}$ IMPMC, Sorbonne Universite

${ }^{5}$ Institut de Minéralogie, Physique des Matériaux et

Cosmochimie, CNRS UMR 7590

${ }^{6}$ Collection Des Cyanobactéries, Institut Pasteur

${ }^{7}$ Muséum National d'Histoire Naturelle

${ }^{8}$ UMR7245 MCAM MNHN-CNRS, Muséum National

d'Histoire Naturelle

${ }^{9}$ iEES-Paris, Sorbonne Université

${ }^{10}$ IMPMC, Sorbonne Université, CNRS UMR 7590, MNHN

Presenting Author: juliette.gaetan@sorbonne-universite.fr

Biomineralization of intracellular amorphous calcium carbonate (iACC) has been recently discovered in widespread and phylogenetically diverse cyanobacteria [1]. This type of biomineralization occurs intracellularly and under out-ofequilibrium thermodynamic conditions [2].

Microcystis is a cyanobacterial genus usually found in freshwater environments and often involved in toxic blooms. Microcystis has been extensively studied especially for mechanisms of toxin production, genetic diversity of its populations, and dynamics of its blooms and their determinants [3]. Here we combined scanning and transmission electron microscopies (SEM and TEM) as well as Fourier transform infrared spectroscopy (FTIR) to study several Microcystis strains and determine whether they form iACC. We linked this phenotypical diversity to the time evolution of the chemical composition of their growth solutions and tested the dependence of their growth on different initial calcium concentrations. Moreover, we conducted a bioinformatics survey using available genomes in order to infer the potential involvement of some genes in iACC-biomineralization. Overall, we detected a phenotypic and genotypic diversity among the tested strains that correlates with their capability to form iACC. Since Microcystis cells can be periodically dominant in some water pools and some of them form iACC, this provides an original case where a mineralogical process may influence the dynamics and genotypic structure of microbial populations. In turn these population dynamics may impact the geochemical cycle of calcium. We will discuss how we aim at estimating the importance of these processes.

[1] Benzerara K. et al (2014) Intracellular Ca-carbonate biomineralization is widespread in cyanobacteria. Proc. Natl. Acad. Sci. USA 111, 10933-10938.
[2] Cam N, Benzerara K, Georgelin T, Jaber M, Lambert $\mathrm{JF}$, Poinsot M, et al. Cyanobacterial formation of intracellular Ca-carbonates in undersaturated solutions. Geobiology. 2017 ; 16(1) : 49-61.

[3] Harke MJ, Steffen MM, Gobler CJ, Otten TG, Wilhelm SW, Wood SA, et al. A review of the global ecology, genomics, and biogeography of the toxic cyanobacterium, Microcystis spp. Harmful Algae. 2016 ; $54: 4-20$ 